Article

\title{
My Lifelong Chemical Contribution From Brazil: New Syntheses of Medium Ring to Macrocyclic Lactones, Related Compounds, and \\ Acyclic Insect Pheromones
}

\author{
Jaswant Rai Mahajan \\ Department of Chemistry, University of Brasilia, Brasilia - DF, Brazil
}

Received: June 5, 1996

\begin{abstract}
Iniciando um modesto esforço em síntese orgânica no começo da década de 70 , sob precárias condições e uma infra-estrutura bem deficiente (infelizmente, ainda persistentes em nossos laboratórios), conseguimos desenvolver vários métodos novos para a preparação dos compostos mencionados no título. Este trabalho apresenta cronologicamente e discute esses métodos.

Starting a modest effort in Organic Synthesis in early $70 \mathrm{~s}$, under poor and difficult circumstances, persistent in our laboratories even today, we have been able to develop several methodologies for the preparation of the title compounds, which are chronologically introduced and discussed in this paper.
\end{abstract}

Keywords: macrocyclic lactones, medium ring lactones, macrolides, acyclic insect pheromones

\section{Introduction}

Recounting and recording my small lifetime research contribution from Brazil, I would like to point out that when I arrived at the then newly founded University of Brasilia (UnB), in August of 1965, our teaching and research conditions, as also in most other parts of Brazil, were rather below the level of many 3rd World countries. However, these conditions as well as the general infrastructure of Brazil, have undergone considerable improvement in the past 30 years. As would be expected under those circumstances, a few active Brazilian organic chemists of that time were engaged in the phytochemical investigations - which still dominate the scene, but with far more sofistication and I also went along the stream, producing about half a dozen publications ${ }^{1-4}$ (Fig. 1).
To undertake Organic Synthesis under those poor and inadequate conditions was thought to be inadvisable and was even counselled against by the then dominant Brazilian Organic Chemists ${ }^{5}$. Nevertheless, in early 70 s, we initiated a modest effort in Organic Synthesis ${ }^{6,7}$ (Fig. 2), which resulted in the development of several new methods for the preparation of medium to macrocyclic ketolactones and some related compounds ${ }^{8}$. More recently, this endeavor has lead us to the synthesis of several acetylenic lactones and the acyclic insect pheromones ${ }^{9}$, as briefly outlined below.

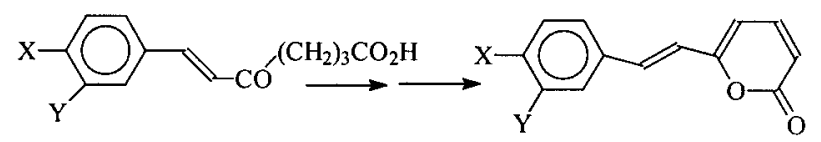

Figure 2. Synthesis of some 6-styryl-2-pyrones ${ }^{6,7}$. a) $\mathrm{X}=\mathrm{Y}=\mathrm{H}$; b) $\mathrm{X}+\mathrm{Y}=\mathrm{OCH}_{2} \mathrm{O}$; c) $\mathrm{X}=\mathrm{Y}=\mathrm{OMe}$; d) $\mathrm{X}=\mathrm{PhCH}_{2} \mathrm{O}, \mathrm{Y}=\mathrm{OMe}$; e) $\mathrm{X}=\mathrm{OH}$, $\mathrm{Y}=\mathrm{OMe}$.

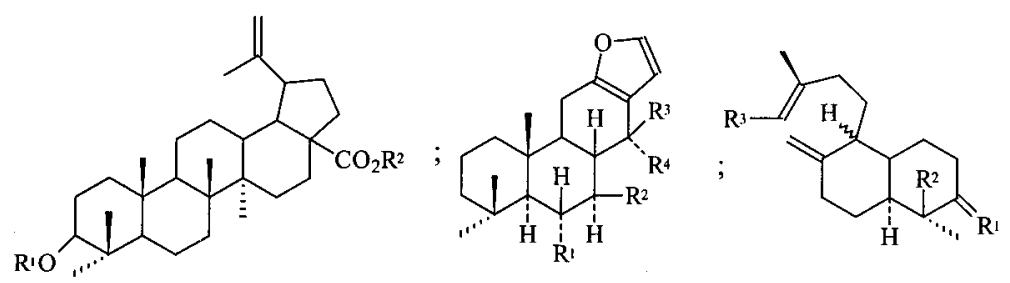

Figure 1. Characterization of various terpenoids isolated from Brazilian flora ${ }^{1-4}$. 
Our first entry into the field, in 1972, came throughthe synthesis of oximino-macrolides by the nitrosation of bicyclic enol ethers ${ }^{10}$, as illustrated in Scheme 1. Although this short communication was almost ignored by the academic research workers, we had the good fortune that the techniques described therein, being simple and economical, got incorporated into a couple of industrial processes ${ }^{11,12}$, which encouraged us to obtain two patents of our own ${ }^{13}$ (Scheme 2). Apart from this, several other substrates containing enol ether, hemi-ketal, enamine and related functional groups were subjected to ring expansion by the oxidative cleavage of the double bond common to the two rings $^{14-24}$ (Scheme 3).

In the meantime, we developed a different approach by the intramolecular alcoholysis of the suitably substituted cyclohexane-1,3-diones (Scheme 4), which was denomi-

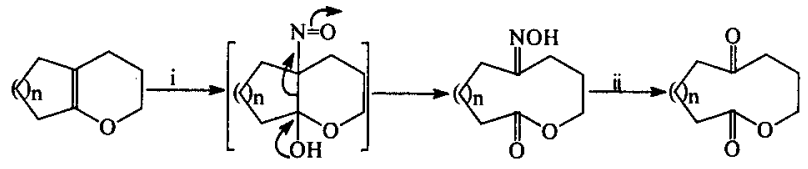

Scheme 1. Synthesis of oximino macrolides ${ }^{10} . n=1-4,8$; i: aq. EtOH, $\mathrm{BuNO}_{2}, \mathrm{H}^{+}$; ii: aq. $\mathrm{NaHSO}_{3}, \mathrm{EtOH}, \triangle$. nated as the Intramolecular Reverse Dieckmann Reaction $^{25}$. Apart from the fact that this new procedure has enabled us to prepare several 9 to 11-membered ketolactones $^{25-31}$ (Scheme 4), it stimulated other research groups to verify the scope of this new methodology (Scheme 5) (2) $^{32}$ or develop analogous methods of ring enlargement, employing the benzenesulfonyl $\left(\phi \mathrm{SO}_{2}\right)^{33}$ or the nitro $\left(\mathrm{NO}_{2}\right)^{34,35}$ group as the electron withdrawing function, shown in Schemes 6 and 7.

Currently, this methodology of ring expansion exploits all sorts of auxiliary groups $\left(\mathrm{RCO}, \mathrm{CO}_{2} \mathrm{R}, \mathrm{CN}, \mathrm{NO}, \mathrm{NO}_{2}\right.$,

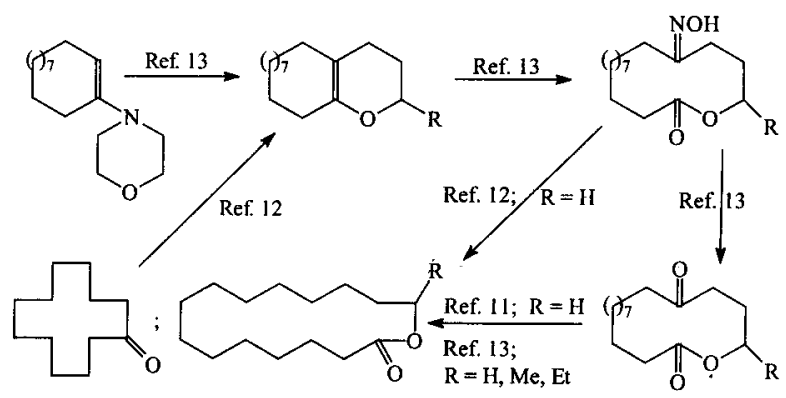

Scheme 2. Different processes for the preparation of pentadecanolide \& its homologs ${ }^{11-13}$.

$$
\text { A: Enol Thio-Ethers, Enamines and Derivatives }{ }^{14,15,19,20,22}
$$

B: Benzo- and Naphthofurans ${ }^{17}$

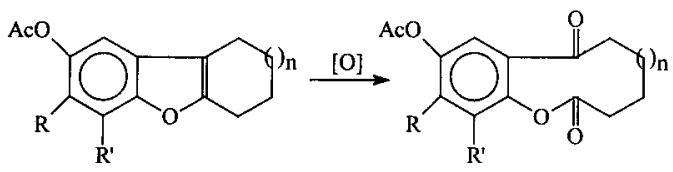

$\mathrm{R}=\mathrm{R}^{\prime}=\mathrm{H} ; \mathrm{R}+\mathrm{R}^{\prime}=\mathrm{HC}: \mathrm{CHCH}: \mathrm{CH} ;$

n: Variable

C: Benzo- and Naphthopyrans ${ }^{18,21}$<smiles>[R]c1ccc2c(c1[R])CC1=C(CCC3CC(C)CC3C1)O2</smiles>

$$
\mathbf{R}=\mathbf{R}^{\prime}=\mathbf{H} ; \mathbf{R}+\mathbf{R}^{\prime}=\mathrm{HC}: \mathrm{CH}-\mathrm{CH}: \mathrm{CH}
$$

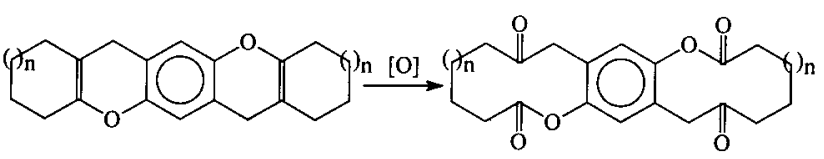

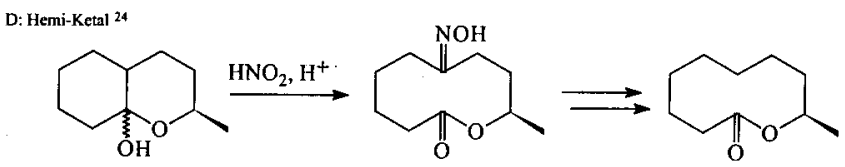

Scheme 3. Oxidative cleavage of enamines, enol ethers, and related compounds ${ }^{14-24}$. 


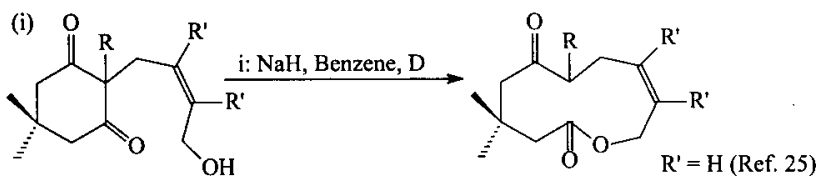

$\mathrm{R}=\mathrm{Me}$, Allyl, Benzyl

$\mathrm{R}^{\prime}+\mathrm{R}^{\prime}=\mathrm{HC}: \mathrm{CH}-\mathrm{CH}: \mathrm{CH}(\operatorname{Ref} .26)$<smiles>[R]C1CCC2(CCC(=O)C[C@@](C)(CC(C)C)CC(=O)C1[R])OCCO2</smiles>

$\mathrm{R}=$ Allyl, Benzyl (Ref. 27)

(iii)

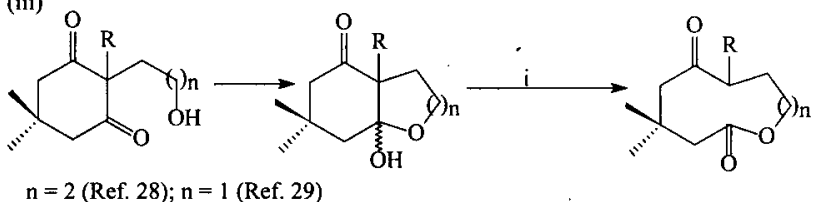

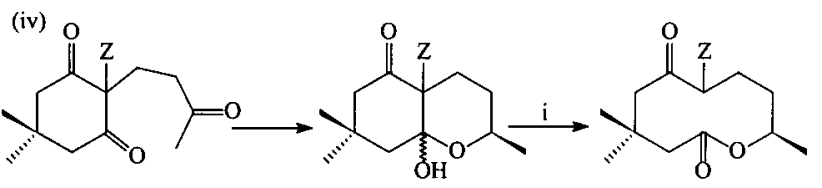

$Z=$ OAc, NHOAc (Ref. 30)

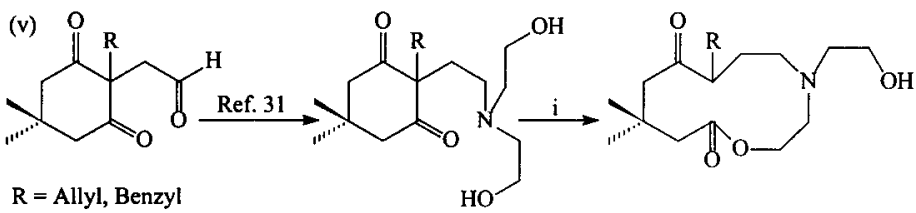

Scheme 4. Synthesis of ketolactones by the intramolecular reverse Dieckmann reaction ${ }^{25-31}$.

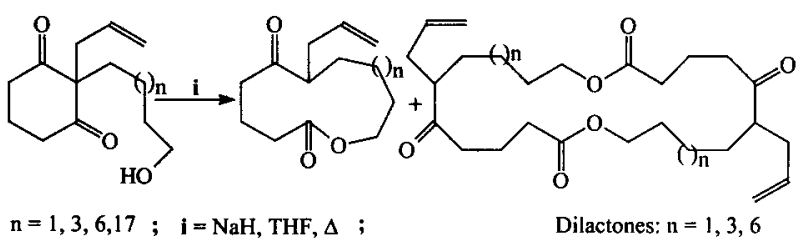

Scheme 5. Preparation of macrocyclic lactones from cyclohexane-1,3diones ${ }^{32}$.

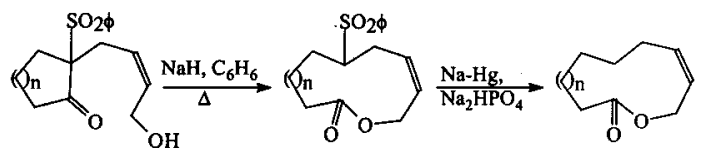

Scheme 6. Synthesis of macrocyclic lactones from 2-phenylsulphonylcycloalkanones ${ }^{33}$.

$\phi \mathrm{SO}_{2}, \mathrm{CH}_{2} \mathrm{~N}^{+} \mathrm{R}_{3}, \mathrm{CH}_{2} \mathrm{OTs}$, etc.) and has been extended to the formation of large carbocyclic systems, translactonizations, transamidations, Zip reaction, etc., as reviewed in some recent publications ${ }^{36-42}$, where our work is also in- a)

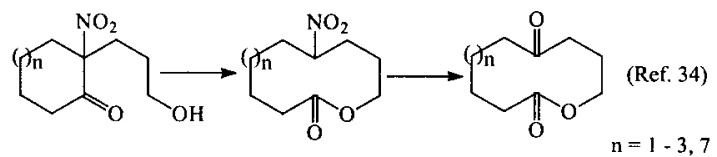

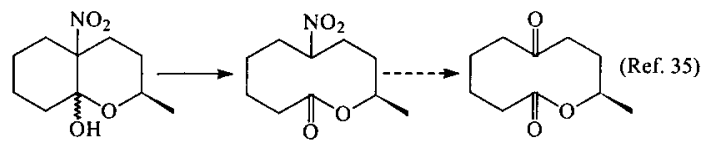

Scheme 7. Ring expansion of 2-nitrocycloalkanones ${ }^{34,35}$.

cluded. Still another application of this procedure is exemplified by the synthesis of some medium ring acetylenic lactones ${ }^{43}$, as illustrated in Scheme 8.

Availability of diversely substituted 9 to 16 membered ketolactones, their precursors, and the related compounds prompted us to examine their ${ }^{13} \mathrm{C}$ and ${ }^{1} \mathrm{H}$ spectra ${ }^{44-49}$, which revealed great conformational flexibility for the 11-16 membered rings ${ }^{44,47}$. In sharp contrast, the 10-membered ones behaved as if in a frozen conformation ${ }^{48}$, while the 9 -mem- 


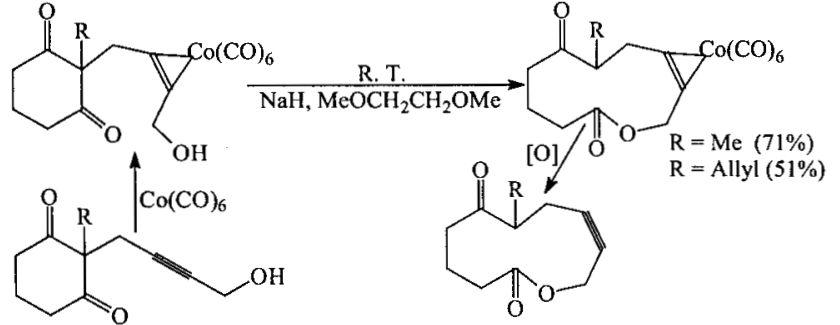

Scheme 8. Preparation of acetylenic lactones from suitable cyclohexane1,3-diones ${ }^{43}$.

bered lactones showed some unusual ${ }^{13} \mathrm{C}$ results ${ }^{49}$, which need further elucidation by $2 \mathrm{D}$ spectra at higher fields.

We would like to point out here that in spite of the great success of the aforementioned ring expansion procedures, based on intramolecular alcoholysis ${ }^{25,32-35}$, there are certain drawbacks to their full development. Thus, for instance, it is necessary to remove the auxiliary function $\left(\mathrm{PhSO}_{2}, \mathrm{NO}_{2} ;\right.$ Schemes 6,7$)$ or the alkyl substituent (R: Me, Allyl, Benzyl; Schemes 4, 5), in order to obtain the natural lactones, which are devoid of such substitution.

As there is no known method for the removal of an alkyl group $\alpha$ to a carbonyl function, we devised a method which places a potentially removable substituent (OAc, NHAc) at the desired position. Although the necessary 10-membered ketolactones, namely, 6-acetoxy- and 6-acetamido-5-oxo9-decanolides were obtained by our standard methodology $^{30}$ (Scheme 9), unfortunately, all our efforts to get rid of the acetoxy or the acetamido pendant have been unsuc-

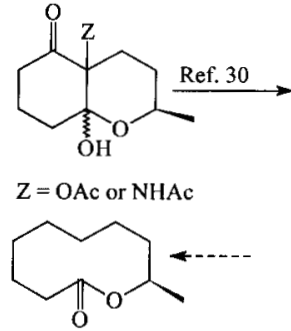

(t)-Phoracantholide I

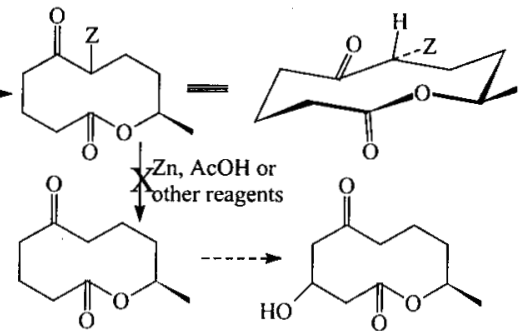

( \pm )-Diplodialide D
Scheme 9. Attempted synthesis of 5-ketodecan-9-olide (desoxydiplodialide $\mathrm{D})^{30}$.

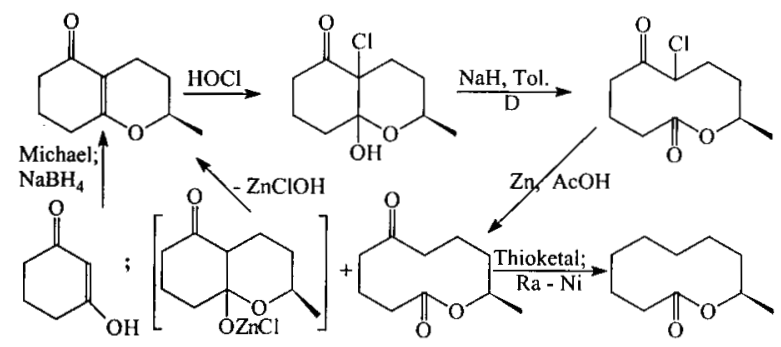

Scheme 10. Synthesis of desoxydiplodialide $d$ and phoracantholide i from dihydroresocinol ${ }^{51}$. cessful so far, using a variety of reagents under diverse conditions $^{49-5 !}$.

Recently, we have been able to develop altogether different protocols for the ring enlargement, starting from both cyclohexane-1,3-diones and cycloalkanones. Thus, in 1990, we described the synthesis of desoxydiplodialide D and phoracantholide I from dihydroresorcinol ${ }^{51}$ (Scheme 10). This synthesis described at least two innovations: the formation of a chlorohydrin from a vinylogous lactone and its ring expansion to an $\alpha$-chloroketolactone. The rest of the steps involve routine adaptations of the known chemical reactions. Fortunately, the reductive elimination $(\mathrm{Zn}$, $\mathrm{AcOH}$ ) of the chloro function was fairly successful, although a small amount of the transannular acylation was also observed ${ }^{51}$ (Scheme 10).

Although we could extend this new procedure to the synthesis of some 10 to 16 -membered $\alpha$-chloroketolactones, we have faced some problems in their dechlorination, using $\mathrm{Zn}-\mathrm{AcOH}$, which reverts them to the starting dihydro-4-pyrones by the intramolecular (transannular) acylation, instead of the desired protonation (Scheme $11)^{52,53}$. While we are looking for alternative methods for this dechlorination, we have been able to convert the intermediate chlorohydrins and/or the chloroketones into the corresponding acetylenic lactones ${ }^{53,54}$, as depicted in Scheme 12. Presently, this transformation provides rather modest yields ( 50 to $60 \%$ ), after laborious purification, and we are investigating its improvement.

However, a parallel study has resulted in a high-yield (65-90\%) new methodology, which converts the vinylo-

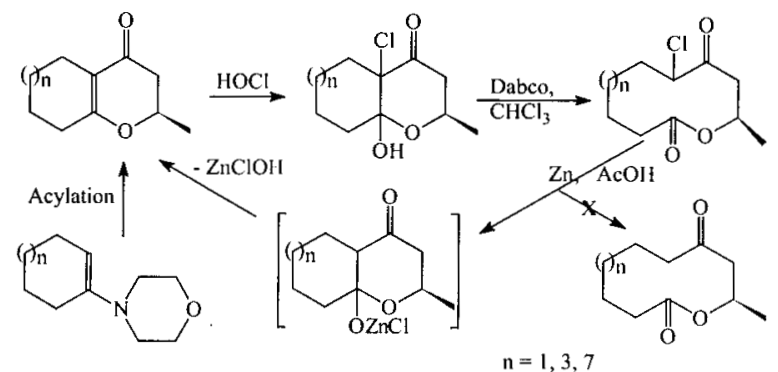

Scheme 11. Ring expansion of vinylogous lactones via chlorohydrins 52,53 .

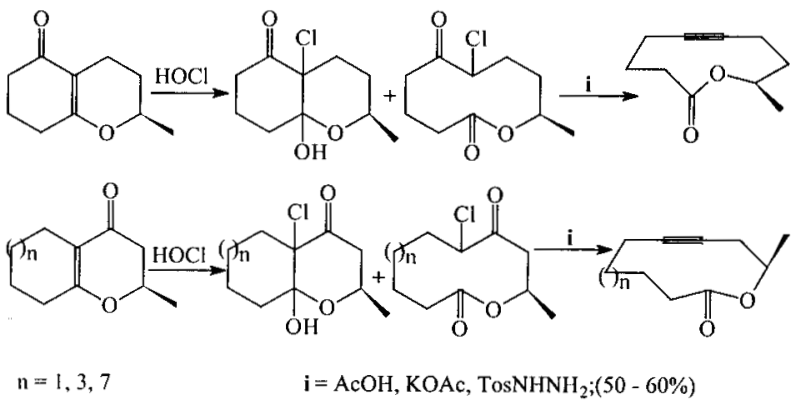

Scheme 12. Conversion of chlorohydrins and/or chloroketones into acetylenic lactones 53,54 . 


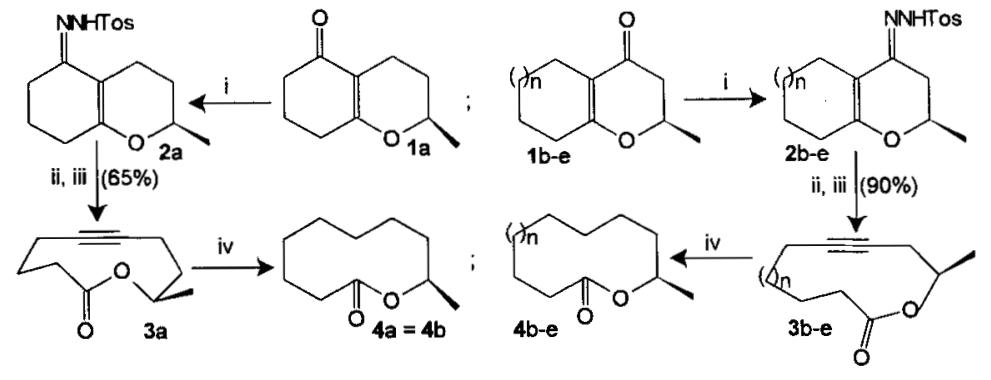

i: Tos $\mathrm{NHNH}_{2}, \mathrm{MeOH}, \mathrm{H}^{+}, \Delta$; ii: aq. $t$ - $\mathrm{BuOH}$, ace tone, NBS, $-10^{\circ} \mathrm{C}$;

iii: aq. $\mathrm{NaHSO}_{3} \cdot 55^{\circ} \mathrm{C} \quad$;iv: $\mathrm{Pd}-\mathrm{C} . \mathrm{H}_{2} ; \quad$ b: $\mathrm{n}=1 ; \mathrm{c}: \mathrm{n}=2 ; \mathrm{d}: \mathrm{n}=3 ; \mathrm{e}: \mathrm{n}=7$

Scheme 13. Synthesis of acetylenic lactones by the fragmentaton reaction of tosylhydrazones ${ }^{53,55}$.

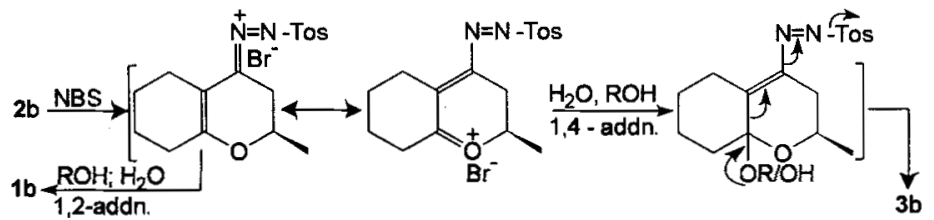

Scheme 14. Mechanism of the fragmentation reaction ${ }^{55}$.

gous lactones (oxabicycloalkenones), via their tosylhydrazones, into the desired acetylenic compounds by a novel fragmentation reaction, carried out under strictly controlled conditions $^{55}$. The resulting 10,12 and 16 -membered acetylenic lactones were hydrogenated to the respective natural products: Phoracantholide I, Dihydrorecifeiolide, and 15Hexadecanolide (Schemes 13, 14) 55,56 .

As several natural lactones, such as, phoracantholides $\mathrm{J}$ and $\mathrm{M}^{57}$, recifeiolide ${ }^{58}$, etc., incorporate $\mathrm{Z}$ or $\mathrm{E}$ double bond in their structure, we carried out the semihydrogenation (Lindlar Pd, $\mathrm{H}_{2}$ ) of these acetylenes to the corresponding Z-compounds ${ }^{59}$ and these in their turn were subjected to isomerization to the E-isomers, completing the synthesis of ( \pm -recifeiolide ${ }^{58}$ and one of its higher (16-membered) homologs ${ }^{60,61}$ (Scheme 15).

Regarding the semi-hydrogenation, we would like to highlight the use of ultrasound radiaton which has proved quite helpful in our small-scale $(0.5-2 \mathrm{mmol})$ experiments ${ }^{59,62}$, lowering the usual hydrogenation time from $8-20 \mathrm{~h}$ to only $0.5-4.0 \mathrm{~h}$. Another point worth mention is the supplier or the source of the Lindlar catalyst. Thus, while the catalyst bought from Aldrich required a drop of quinoline for successful semi-hydrogenation, the one purchased from Fluka did not need it.

Of the several methods described for the catalytic isomerization ( $\phi \mathrm{SH}, \mathrm{AIBN}, \mathrm{h} v / \Delta ; \phi \mathrm{SS} \phi, \mathrm{h} v ; \mathrm{I}_{2}, \mathrm{~h} v$, etc. $)^{63}$ or the chemical inversion of the olefinic double bond (i. NCS or NBS, TFA; ii. NaI, DMF, $\Delta)^{64}$, we found out that the catalytic technique described by Sonnet $\left(\mathrm{NaNO}_{2}\right.$ and $\left.\mathrm{HNO}_{3}\right)^{65}$ was the most convenient and economical for the case in hand, affording the 12 and 16 membered E-lactones in over $90 \%$ yield, both in mass and stereochemical terms. However, these optimum conditions for $\mathrm{Z}$ to $\mathrm{E}$ isomerization were not successful with the 10 membered lactones,

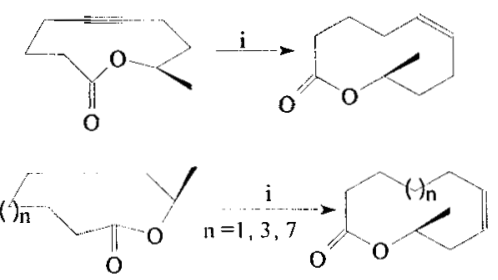

i: Lindlar Pd, Quinoline, $\mathrm{H}_{2}$; ii: $\mathrm{HNO}_{3}, \mathrm{NaNO}_{2}, \Delta$;
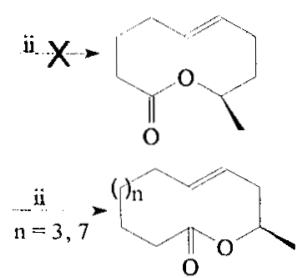

( \pm )-Re cifeiolide $(n=3)$

Scheme 15. Semi-hydrogenation of acetylenic lactones to z-alkenes and their isomerization to E- compounds ${ }^{59-61}$.

which did not seem to undergo appreciable change to the respective $\mathrm{E}$ compounds $\left({ }^{1} \mathrm{H}\right.$ - and $\left.{ }^{13} \mathrm{C}-\mathrm{NMR}\right)$. In contrast, the chemical inversion procedure (TFA, NBS; NaI, DMF, $\Delta)^{64}$ proved clean (TLC, 'H-NMR) only for the 16 membered lactone, furnishing the $\mathrm{E}$ isomer in an inferior yield $(66 \%)$; the other substrates gave complex mixtures ${ }^{53,61}$.

The reluctance of the 10-membered Z-cycloalkenes to isomerize to the E-compounds, possibly reflects their relative structural rigidity and the geometrical restraints of an $\mathrm{E}$ bond in the medium size ring. In contrast, the open chain $Z$-alkenes undergo $Z$ to $E$ isomerization quite satisfactorily, both by the above catalytic technique and the chemical inversion procedure ${ }^{53,64,65}$.

As the $\mathrm{Z}$ and $\mathrm{E}$ lactones were not easily distinguishable in the IR region and differed only slightly in ${ }^{1} \mathrm{H}-\mathrm{NMR}$ spectra at $90 \mathrm{MHz}$, we resorted to their ${ }^{1} \mathrm{H}$ and ${ }^{13} \mathrm{C}$ spectra at $200 / 50 \mathrm{MHz}$ (PND, DEPT, ${ }^{1} \mathrm{Hx}{ }^{1} \mathrm{H}$ and ${ }^{1} \mathrm{Hx}^{13} \mathrm{C} \mathrm{COSY}$, etc.). Even at this strength, the most evident distinguishing features, as expected, are the chemical shifts of the allylic carbon atoms, which are 5 to $8 \mathrm{ppm}$ upfield in the $\mathrm{Z}$ compounds, as compared to the respective shifts in the $\mathrm{E}$ isomers ${ }^{66}$. Another point worth mention is the strong splitting of various methylene protons into an ABXn pattern, 
especially in the $Z$ lactones, thus revealing their comparatively rigid nature compared with the $\mathrm{E}$ macrolides as well as the acyclic derivatives ${ }^{53,61,66}$.

Moreover, we would like to point out that a careful examination of the PND spectra revealed that although the $Z$-decenolides were free from the respective $E$ compound, both the $\mathrm{Z}$ and $\mathrm{E} 12$ - and 16-membered macrolides were contaminated with small quantities of the respective geometrical isomer.

Now coming to the synthesis of insect pheromones, an important and a rapidly growing class, largely representing diversely functionallized acyclic organic compounds ${ }^{67}$, we would like to point out that an easy availability of the acetylenic as well as ethylenic lactones (vide supra), encouraged us to proceed with their transformation into several alkenols and their acetates ${ }^{53,66,68}$ (Scheme 16), some of which are components of important pheromones ${ }^{67}$.

Thus, methanolysis of the Z-lactones gave the corresponding hydroxy-esters, which on mesylation furnished the respective mesylates. Lithium aluminum hydride reduction of the latter in ether afforded the Z-alkenols, which were acetylated to the corresponding acetates. Of these, (Z)-5-decenyl acetate is the pheromone component of the turnip moth (Agrotis segetum) ${ }^{67,69}$, while (Z)-8-dodecenyl acetate constitutes the sex pheromone of the oriental fruit moth (Grapholita molesta) ${ }^{67}$. These two compounds have been synthesized earlier ${ }^{67}$.

Both the catalytic isomerization $\left(\mathrm{NaNO}_{2}, \mathrm{HNO}_{3}\right)^{65}$ and the chemical inversion (TFA, NBS; NaI, DMF, $\Delta)^{64}$ of the $\mathrm{Z}$ alkenyl acetates worked well and lead to the corresponding $E$ acetates in good (90-95\%) yield. Nevertheless, the catalytic technique ${ }^{65}\left(2 \mathrm{M} \mathrm{NaNO}_{2}, 2 \mathrm{M} \mathrm{HNO}_{3}, 70-75^{\circ} \mathrm{C}, 1\right.$ $\mathrm{h}$ ) is far more convenient and economical. Of the $\mathrm{E}$ isomers, presently, only (E)-8-dodecenyl acetate is the minor component of the pheromone of the oriental fruit moth (Grapholita molesta), mentioned earlier ${ }^{67}$.

We would like to point out here that the alternative route to these $\mathrm{E}$ alkenyl acetates, through the respective transformations of the $\mathrm{E}$ lactones, is rather limited and less attractive, because the $Z$ to $E$ isomerization works better in the acyclic compounds as compared with the cyclic ones (lactones), as already discussed else where ${ }^{53,61,66}$.

Still another variation was tested with the opening of one member of the acetylenic lactones: 6-decyn-9-olide (Scheme 16, item B). However, reduction of the corresponding mesiloxy-ester, with $\mathrm{LiAlH}_{4}$ in ether, required

A: From Ethylenic Lactones ${ }^{53,68}$

(a)

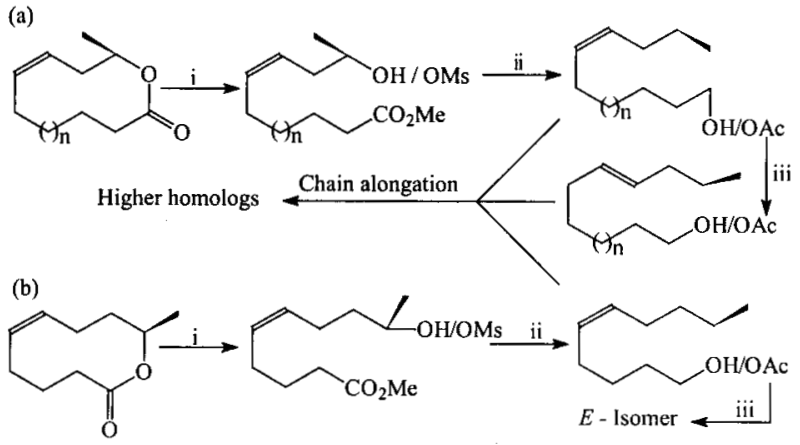

n: Variable; i: Methanolysis \& mesylation ; ii: $\mathrm{LiAlH}_{4}$ \& acetylation; iii: $\mathrm{NaNO}_{2}, \mathrm{HNO}_{3}, \Delta$

B: From 6-Decyn-9-olide
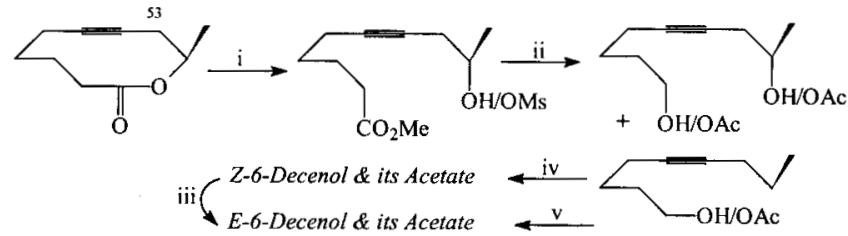

$\mathrm{i}, \mathrm{ii}$ and $\mathrm{iii}$, as just above in (A);

iv: Lindlar Pd, $\mathrm{H}_{2}$ \& acetylation; v: $\mathrm{LiAlH}_{4}$, diglyme, reflux, $24 \mathrm{~h}$ \& acetylation.

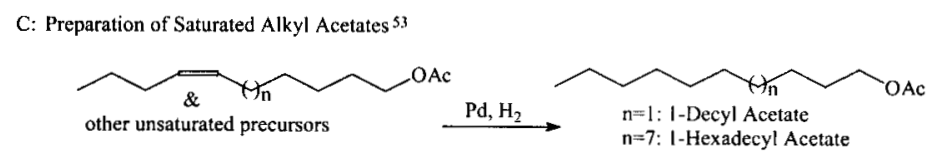

Scheme 16. Preparation of acyclic pheromones from ethylenic and acetylenic lactones ${ }^{53,66,68}$. 
much lower initial reaction temperature $\left(-100^{\circ} \mathrm{C}\right.$ as compared with the usual $-15^{\circ} \mathrm{C}$ ), but still gave a mixture of the desired monol and the unwanted diol, which had to be separated by column chromatography of the respective acetates $^{53}$. Nevertheless, this path has the advantage of leading to both the $Z$ and $E$ isomers directly from the acetylenic precursor. Thus, semi-hydrogenation $\left(\mathrm{H}_{2}\right.$, Lindlar cat.) of 6-decynyl acetate furnished (Z)-6-decenyl acetate, while its reduction with $\mathrm{LiAlH}_{4}$ in refluxing diglyme ${ }^{70}$ gave directly (E)-6-decen-1-ol, which was converted into the respective acetate (Scheme 16, item B).

Apart from furnishing the acetylenic intermediates as well as both the $\mathrm{Z}$ and $\mathrm{E}$ alkenyl alcohols and their esters, the present methodology also opens an access to the saturated pheromones, either by the full hydrogenation of the unsaturated precursores or by the systematic elaboration of the saturated lactones. We chose to prepare 1-decyl acetate and 1-hexadecyl acetate, pheromone components of the turnip moth (Agrotis segetum) ${ }^{69}$ and the male butterfly Lycorea ceres ceres $^{71}$, respectively, from the corresponding Z-alkenyl acetates (Scheme 16, item C).

The infrared and $90 \mathrm{MHz}{ }^{1} \mathrm{H}-\mathrm{NMR}$ spectra do not clearly differentiate between the $Z$ and $E$ alkenyl acetates. Consequently, we resorted to their $200 / 50 \mathrm{MHz}{ }^{1} \mathrm{H}$ and ${ }^{13} \mathrm{C}$ spectra (PND, DEPT, ${ }^{1} \mathrm{Hx}^{1} \mathrm{H}$ and ${ }^{1} \mathrm{Hx}^{13} \mathrm{C} \mathrm{COSY}$, etc.), where the most evident distinguishing feature, as expected, is the chemical shift of the allylic carbon atoms, which are 4 to 6 ppm upfield in the $Z$ compounds as compared with the respective atoms in the $\mathrm{E}$ isomers ${ }^{66}$. Moreover, close examination of the olefinic carbon atoms in the PND spectra revealed that all the $E$ alkenyl acetates were contaminated with $5-10 \%$ of the corresponding $Z$ isomer, while only the (Z)-8-dodecenyl acetate and (Z)-12-hexadecenyl acetate contained $5-10 \%$ of the respective $E$ compound, as also present in the precursor Z-lactones ${ }^{53,61}$.

Concurrently, we have also developed an alternative route to these pheromones, as outlined in Scheme 17. It may be noticed here that our strategy differs from the conventional acetylenic chemistry, Wittig olefination and the related reactions usually employed for the preparation of acetylenic and olefinic compounds ${ }^{67}$.

Part A of Scheme 17 outlines our general approach to the acyclic pheromones from cycloalkanones ${ }^{9,68,72}$, while part $B$ illustrates the preparation of methyl E-6-nonenoate and E-6-nonenol, two components of the male sex pheromone of the Mediterranean fruit fly (Ceratitis capitata Wiedmann), from cyclohexanone ${ }^{73}$. Furthermore, the corresponding acetate (E-6-nonenyl acetate) is a synthetic attractant (parapheromone) for the females of the melon fruit fly (Dacus cucurbitae Coquillet) ${ }^{67,73,74}$. The chemical transformations shown in Scheme 17B, though very simple, involve quite a few crucial steps. Thus, the

A: General Strategy

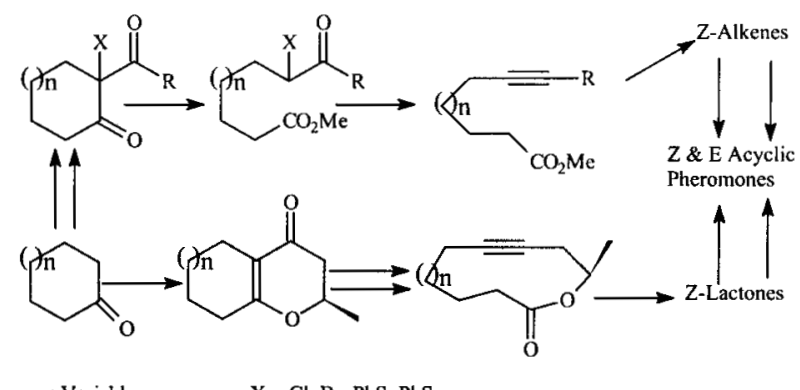

B: Preparation of E-6-Nonenoate, E-6-Nonenol and its Acetate from Cyclohexanone ${ }^{3}$

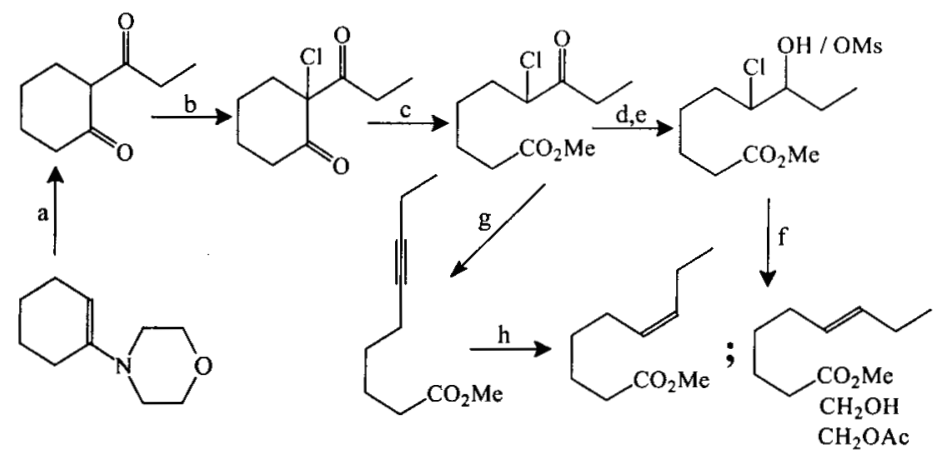

Scheme 17. Acyclic insect pheromones from cycloalkanones ${ }^{9,68,72}$. Reagents and conditions: a) $\mathrm{Acylation}$; b) $\mathrm{NaClO}^{+} \mathrm{H}^{+}, \mathrm{EtOAC}^{\circ} \mathrm{SO} \mathrm{SO}_{2} \mathrm{Cl}_{2}, \mathrm{CCl}_{4}$; $\mathrm{c}$ ) Acetone, $\mathrm{MeOH}, \mathrm{K}_{2} \mathrm{CO}_{3}$, reflux; d) $\mathrm{MeOH}, \mathrm{NaBH}_{4}$; e) $\mathrm{MsCl}, \mathrm{Et} 3 \mathrm{~N}, \mathrm{CH}_{2} \mathrm{Cl}_{2}$; f) $\mathrm{NaI}, \mathrm{DMSO}, \Delta$; g) $\mathrm{TosNHNH}, \mathrm{AcOH}, \mathrm{KOAc}$; h) Lindlar $\mathrm{Pd}, \mathrm{H}_{2}$, Quinoline. 
methanolysis of the 2-propionyl-2-chlorocyclohexanone has to be carried out in very carefully controlled conditions $\left(\mathrm{MeOH} \text {, acetone, } \mathrm{K}_{2} \mathrm{CO}_{3}, \Delta\right)^{73,75}$ to avoid the Favorsky rearrangement and other possible side reactions. The resulting chloroketo-ester can then be transformed into an olefinic or an acetylenic ester by entirely different routes and strategies. Of course, the acetylenic ester can be converted in almost stereospecific manner into the corresponding Z-alkene and subsequently isomerized to the E-alkenoate, both capable of easy reduction $\left(\mathrm{LiAlH}_{4}\right)$ to the respective alkenols, some of which are components of insect pheromones. Otherwise, subsequent acetylation or chain alongation (Scheme 16A), via mesylate, tosylate or the halide derivative, completes the synthesis of the desired pheromone and/or its higher homologs for biological evaluation.

We are presently engaged in the preparation of several such compounds, represented by the general formula: $\quad \mathrm{H}_{3} \mathrm{C}-\left(\mathrm{H}_{2} \mathrm{C}\right)_{\mathrm{m}}-\mathrm{CH}: \mathrm{CH}-\left(\mathrm{CH}_{2}\right)_{\mathrm{n}}-\mathrm{OH} / \mathrm{OAc}$, where $\mathrm{m}$ and $\mathrm{n}$ can be varied according to the desired target pheromone. Thus, Scheme 18 shows another example of our general methodology for preparing acyclic compounds, where the well-known phenylsuphoxide elimination is exploited to generate a double bond at the penultimate carbon of the starting cycloalkanone $^{76}$. The resulting enone can then lead to alkenes having unsaturation either at the penultimate or the ultimate carbon atom of the starting ketone. Moreover, the sulphide and sulphoxide intermediates may also be used to generate a triple bond, as illustrated in Scheme 18. We are also examining the alternative path using selenium analogs.

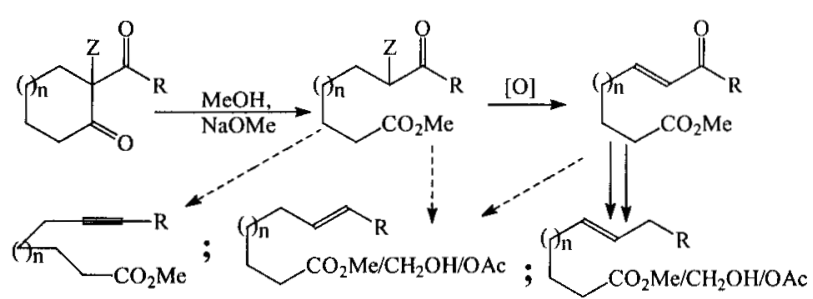

$\mathrm{Z}: \mathrm{SPh}, \mathrm{SePh} ; \mathbf{R}$ and $\mathbf{n}$ are variable.

Scheme 18. Synthesis of acyclic pheromones via organo-sulphur and organo-selenium intermediates 76 .

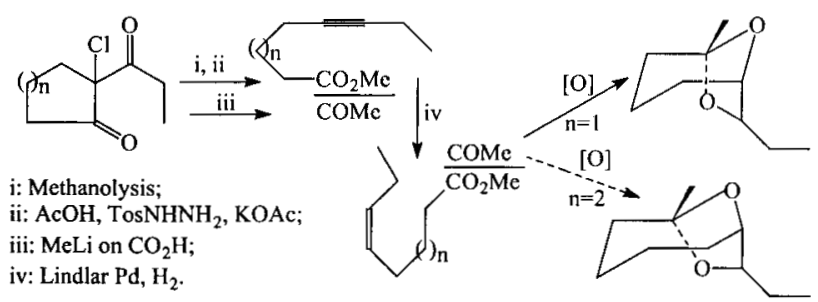

Scheme 19. Studies towards the synthesis of $( \pm)$-brevicomins and their homologs ${ }^{77}$.
Furthermore, easy availability of acetylenic as well as ethylenic esters, having the unsaturation generated, regiospecifically, at the last carbon of the starting cycloalkanone, prompted us to undertake their conversion into the corresponding methyl ketones ${ }^{77}$ (Scheme $19)$, bearing in mind that both the $Z$ and $E$ 6-nonen-2ones have been transformed into the endo- and exobrevicomins by diverse oxidizing agents ${ }^{67}$. We also wanted to test if the brevicomin homologs incorporating a 7- and 5-membered ketal, instead of the 6- and 5 -membered one encountered in brevicomins, could be prepared from E/Z 7-decen-2-ones. This work is still in progress.

\section{Acknowledgments}

First of all, my thanks to the the Organizing Committee of the 7th Brazilian Meeting on Organic Synthesis (7th BMOS) and its Executive Secretary, Professor Joaquim Fernando Mendes da Silva, for inviting me to participate in this prestigious event held under the auspices of the Brazilian Chemical Society and its Rio de Janeiro section. I also thank my present collaborators (H.C de Araújo, I.S. Resck, C.R. da Silva, G.H. Aspesi, K.V. Arrelaro, and M.V. Lopes) as well as my former students (M.B. Monteiro, G.A.L. Ferreira, B.J. Nunes, H. de Carvalho, J.R. Botelho, and L.M.F. Tresvenzol), all of them mentioned in the respective references, for diligently carrying out the experimental work. The financial support granted to my research projects by $\mathrm{CNPq}$, FAP-DF, and UnB is also gratefully acknowledged.

\section{References and Notes}

1. Araújo, H.C.; Mahajan, J.R.; Gottlieb, O.R.; MagaIhães, M.T. An. Acad. Bras. Ciênc. 1966, 38, 429.

2. Mahajan, J.R.; Monteiro, M.B. An. Acad. Bras. Ciênc. 1970, 42 (supplement), 103; ibid. 1972, 44, 51; J. Chem. Soc. (Perkin Trans. I) 1973, 520.

3.Fascio, M.; Mors, M.B.; Gilbert, B.; Mahajan, J.R.; Monteiro, M.B.; Santos Filho, D; Wichnewshi, W. Phytochemistry 1976, 15, 201.

4. Mahajan, J.R.; Ferreira, G.A.L. An. Acad. Bras. Ciênc. 1971, 43, 611.

5. Mahajan. J.R. In Química Orgânica Sintética: Brasil - 1987; Comasseto, J.V., Ed.; Volume Comemorativo do $2^{\circ}$ BMOS; Copy Service; USP - São Paulo, 1987; pp 71-74.

6. Araújo, H.C.; Mahajan, J.R. An. Acad. Bras. Ciênc. 1970, 42 (Supplement), 129.

7. Mahajan, J.R.; Araújo, H.C. J. Org. Chem. 1971, 36, 1832.

8. Mahajan, J.R.; Araújo, H.C. Ciênc. \& Cult. 1980, 32, 893.

9. (a) Mahajan. J.R. In Organic Synthesis in Brazil: An Overview; Comasseto, J.V.; Ferreira, J.T.B., Eds.; 
Editoração Eletrônica \& Multimídia: São Carlos-SP, 1994; pp 79-87; (b) Mahajan, J.R. $10^{\text {th }}$ International Conference on Organic Synthesis (Icos-10), Bangalore, India, 1994, Abstracts: ISP-27, p 81.

10. Mahajan, J.R.; Ferreira, G.A.L.; Araújo, H.C. $J$. Chem. Soc. Chem. Comm. 1972, 1078.

11.Zakharkin, L.I.; Pryanishnikov, A.P.; Guseva, V.V.; USSR Pat. 521.274, 1976; C. A. 86: 5336z 1977.

12. Bauer, K.; Koerber, A. Ger. Offen 2.731 .543 ; C. A. 90: 151.607n (1979); vide U.S. Pat. 4187 222, 1980.

13. Mahajan, J.R.; Araújo, H.C. PI 8.108.358 (1981); C. A. 100 : $138.981 \mathrm{k}$ (1984); PI 8.108 .582 (1981); C. A. 101: $210.984 \mathrm{~d}(1984)$.

14. Mahajan, J.R.; Ferreira, G.A.L.; Araújo, H.C.; Nunes, B.J. Synthesis 1973, 313.

15. Mahajan, J.R.; Ferreira, G.A.L.; Araújo, H.C.; Nunes, B.J. Tet. Lett. 1974, 3025.

16. Araújo, H.C.; Ferreira, G.A.L.; Mahajan, J.R. $J$. Chem. Soc. (Perkin Trans. I) 1974, 2257.

17. Mahajan, J.R.; Araújo, H.C. Synthesis 1975, 54.

18. Mahajan, J.R.; Araújo, H.C. Synthesis 1976, 111.

19. Mahajan, J.R.; Ferreira, G.A.L.; Araújo, H.C.; Nunes, B.J. Synthesis 1976, 112.

20. Araújo, H.C.; Mahajan, J.R. Synthesis 1978, 228.

21. Mahajan, J.R.; Monteiro, M.B. Bull. Chem. Soc. Japan 1978, 5l, 1207.

22. Mahajan, J.R.; Nunes, B.J.; Araújo, H.C.; Ferreira, G.A.L. J. Chem. Res. 1979: (S), 284; (M), 3158-3173.

23. Mahajan, J.R.; Araújo, H.C. Synthesis 1980, 64.

24. Mahajan, J.R.; Araújo, H.C. Synthesis 1981, 49.

25. Mahajan, J.R. Synthesis 1976, 110.

26. Mahajan, J.R.; Carvalho, H. Synthesis, 1979, 518.

27. Mahajan, J.R.; Monteiro, M.B. J. Chem. Res. 1980: (S), 264; (M), 3275-3293.

28. Mahajan, J.R.; Resck, I.S. Synthesis 1980, 998.

29. Mahajan, J.R.; Botelho; J.R. ; Resck, I.S. J. Braz. Chem. Soc. 1990, l, 13.

30. Mahajan, J.R.; Monteiro, M.B. Ciênc. \& Cult. 1981, 33 (7, Supplement), 368.

31. Mahajan, J.R.; Resck, I.S. Ciênc. \& Cult. 1982, 34 (7, Supplement), 426.

32. Scott, P.W.; Harrison, I.T.; Bittner; S. J. Org. Chem. 1981, 46, 1914.

33. Bhat, V.; Cookson, R.C. J.C.S., Chem. Comm. 1981, 1123.

34. Cookson, R.C.; Ray, P.S. Tet. Lett. 1982, 3521.

35. Kostova, K.; Lorenzi-Riatsch, A.; Nakashita, Y.; Hesse, M. Helv. Chim. Acta, 1982, 65, 249.

36. Kocovsky, P.; Turecek, F.; Hajicek, J., Eds.; Synthesis of Natural Products: Problems of Stereoselectivity; CRC Press: Boca Raton, Florida, 1986. Vol. 2.
37. Hesse, M. In Biologically Active Natural Products; Hostettmann, K.; Lea, P.J., Eds.; Oxford Science Publications, Clarendon Press: Oxford, 1987.

38. Stach, H.;. Hesse, M Tetrahedron 1988, 44, 1573.

39. Hesse, M. Ring Enlargement in Organic Chemistry; VCH: Weinheim, 1991.

40. Trost, B.M.; Fleming, I, Eds.; Comprehensive Organic Synthesis: Selectivity, Strategy and efficiency in Modern Organic Synthesis; Pergamon Press: Oxford, 1991; Vol. 2.

41. Roxburgh, C.J. Tetrahedron 1993, 49, 10749; ibid. $1995,51,9767$.

42. Rousseau, G. Tetrahedron, 1995, 51, 2777.

43. Schore, N.E.; Najdi, S.D. J. Org. Chem., 1987, 52, 5296.

44. Mahajan, J.R.; Araújo, H.C. Can. J. Chem. 1977, 55, 3261 .

45. Mahajan, J.R. J. Chem. Soc. (Perkin Trans. I) 1978, 1434.

46. Fraser, R.R.; Roustan, J.L.A.; Mahajan, J.R. Can. J. Chem. 1979, 57, 2239.

47. Mahajan, J.R. J. Braz. Chem. Soc. 1990, 1, 135.

48. Mahajan, J.R. 4th Meeting of NMR Users 1993, Abstracts: p 87; Anais, 322.

49. Mahajan, J.R. unpublished results.

50. House, H.O. Modern Synthetic Reactions, 2nd Edition; Benjamin: Menlo Park, 1972; pp 158-162.

51. Mahajan, J.R.; Silva, C.R. J. Braz. Chem. Soc., 1990, 1,87 .

52. Mahajan, J.R.; Resck, I.S.; Araújo, H.C.; Tresvenzol, L.M.F.; Aspesi, G.H. 15th Annual Meeting of SBQ 1992, Abstracts: QO - 009.

53. Resck, I.S. Ph.D Thesis, University of Brasília, Department of Chemistry, 1990.

54. Mahajan, J.R.; Resck, I.S. 16th Annual Meeting of $S B Q, 1993$, Abstracts: QO - 22.

55. Mahajan, J.R.; Resck, I.S. J. Chem. Soc., Chem. Comm. 1993, 1748.

56. Mahajan, J.R.; Resck, I.S. 4th Meeting of NMR Users 1993, Abstracts: p 85; Anais, 319.

57. Moore, B.P.; Brown, W.V. Aust J. Chem. 1976, 29, 1365 .

58. (a) Vesonder, R.F.; Stodola, F.H.; Wickerham, L.J.; Ellis, J.J.; Rolwedder, W.K. Can. J. Chem. 1971, 49, 2029. (b) Trost, B.M.; Verhoeven, T.R. J. Am. Chem. Soc. 1980, 102, 4743; (c) Wasserman, H.H.; Gambale, R.J.; Pulwer, M.J. Tetrahedron 1981, 37, 4059.

59. Resck, I.S.; Mahajan, J.R. 17th Annual Meeting of SBQ 1994, Abstracts: QO - 42.

60. Resck, I.S.; Mahajan, J.R. 6th Brazilian Meeting on Organic Synthesis (6th BMOS), 1994, Abstracts: p 69.

61. Mahajan, J.R.; Resck, I.S. Synth. Commun. 1996, in press. 
62. Mason; T.J.; Lorimer, J.P. Sonochemistry: Theory, Applications and Uses of Ultrasound in Chemistry; Ellis Horwood Limited: Chichester; 1988, p 91.

63. Larock, R.C. Comprehensive Organic Transformations: Guide to Fundamental Group Preparations; VCH: Weinheim/New York, 1989; see Isomerization of Alkenes.

64. Sonnet, P.E. J.Org. Chem. 1980, 45, 154.

65. Sonnet, P.E. J.Org. Chem. 1974, 39, 3793.

66. Mahajan, J.R.; Resck, I.S.; Braz-Filho, R.; Carvalho, M.G. 5th Meeting of NMR Users 1995; Abstracts: $\mathrm{p}$ 38; Anais, in press.

67. Mori, K. In The Total Synthesis of Natural Products; ApSimon, J., Ed.; Wiley: New York, 1992, and pertinent references cited therein.

68. Resck, I.S.; Mahajan, J.R.; 6th Brazilian Meeting on Organic Synthesis (6th BMOS) 1994, Abstracts: p 94.

69. Olsson, A.-M.; Jonsson, J.A.; Thelin, B.; Liljefors, T. J. Chem. Ecol. 1983, 9, 375.
70. Schwarz, M.; Graminski, G.F.; Waters, R.M. J. Org. Chem. 1986, 51, 260.

71. Meinwald, J.; Meinwald, Y.C. J. Am. Chem. Soc. 1966, 88, 1305; Meinwald, J.; Meinwald, Y. C.; Wheeler, J.W.; Eisner, T. Science 1966, 151, 583.

72. Mahajan, J.R.; Tresvenzol, L.M.F.; Silva, C.R.; Araújo, H.C. 5th BMOS 1992, Abstract: PS - 021.

73. Mahajan, J.R.; Tresvenzol, L.M.F. J. Braz. Chem. Soc. 1993, 4, 179.

74. Jacobson, M.; Keiser, I.; Chambers, D.L.; Miyashita, D.H.; Harding, C. J. Med. Chem. 1971, 14, 236.

75. Mahajan, J.R.; Araújo, H.C., unpublished results.

76. Araújo, H.C.; Arrelaro, K.V.; Lopes, M.V.; Mahajan, J.R. 18th annual meeting of SBQ 1995, Abstracts: QO-170.

77. Mahajan, J.R.; Aspesi, G.H.; Lopes, M.V. 18 th annual meeting of $S B Q 1995$, Abstracts: QO-029. 